\title{
Decompressive hemicraniectomy: predictors of functional outcome in patients with ischemic stroke
}

\author{
Badih Daou, MD, ${ }^{1}$ Anthony P. Kent, BA, ${ }^{2}$ Maria Montano, MPH, ${ }^{2}$ Nohra Chalouhi, MD, ${ }^{1}$ \\ Robert M. Starke, MD, ${ }^{3}$ Stavropoula Tjoumakaris, MD, ${ }^{1}$ Robert H. Rosenwasser, MD, ${ }^{1}$ and \\ Pascal Jabbour, MD'
}

\begin{abstract}
1Department of Neurological Surgery, Thomas Jefferson University and Jefferson Hospital for Neuroscience, Philadelphia; ${ }^{2}$ Sidney Kimmel Medical College, Thomas Jefferson University, Philadelphia, Pennsylvania; and ${ }^{3}$ Department of Neurological Surgery, University of Virginia Health System, Charlottesville, Virginia
\end{abstract}

\begin{abstract}
OBJECTIVE Patients presenting with large-territory ischemic strokes may develop intractable cerebral edema that puts them at risk of death unless intervention is performed. The purpose of this study was to identify predictors of outcome for decompressive hemicraniectomy $(\mathrm{DH})$ in ischemic stroke.
\end{abstract}

METHODS The authors conducted a retrospective electronic medical record review of 1624 patients from 2006 to 2014 . Subjects were screened for DH secondary to ischemic stroke involving the middle cerebral artery, internal carotid artery, or both. Ninety-five individuals were identified. Univariate and multivariate analyses were performed for an array of clinical variables in relationship to functional outcome according to the modified Rankin Scale (mRS). Clinical outcome was assessed at 90 days and at the latest follow-up (mean duration 16.5 months).

RESULTS The mean mRS score at 90 days and at the latest follow-up post-DH was 4. Good functional outcome was observed in $40 \%$ of patients at 90 days and in $48 \%$ of patient at the latest follow-up. The mortality rate at 90 days was $18 \%$ and at the last follow-up $20 \%$. Univariate analysis identified a greater likelihood of poor functional outcome (mRS scores of 4-6) in patients with a history of stroke (OR 6.54 [95\% Cl 1.39-30.66]; $p=0.017)$, peak midline shift $(\mathrm{MLS})>$ $10 \mathrm{~mm}$ (OR 3.35 [95\% Cl 1.33-8.47]; $p=0.011)$, or a history of myocardial infarction (OR 8.95 [95\% Cl 1.10-72.76]; $p=$ 0.04). Multivariate analysis demonstrated elevated odds of poor functional outcome associated with a history of stroke (OR 9.14 [95\% Cl 1.78-47.05]; $p=0.008), M L S>10 \mathrm{~mm}$ (OR 5.15 [95\% Cl 1.58-16.79; $p=0.007$ ), a history of diabetes (OR 5.63 [95\% Cl 1.52-20.88]; $p=0.01)$, delayed time from onset of stroke to $\mathrm{DH}(\mathrm{OR} 1.32$ [95\% Cl 1.02-1.72]; $p=$ 0.037 ), and evidence of pupillary dilation prior to $\mathrm{DH}(\mathrm{OR} 4.19$ [95\% $\mathrm{Cl} 1.06-16.51] ; p=0.04)$. Patients with infarction involving the dominant hemisphere had higher odds of unfavorable functional outcome at 90 days $(\mathrm{OR} 4.73[95 \% \mathrm{Cl}$ 1.36-16.44]; $p=0.014$ ), but at the latest follow-up, cerebral dominance was not significantly related to outcome (OR 1.63 [95\% Cl 0.61-4.34]; $p=0.328$ ).

CONCLUSIONS History of stroke, diabetes, myocardial infarction, peak MLS $>10 \mathrm{~mm}$, increasing duration from onset of stroke to $\mathrm{DH}$, and presence of pupillary dilation prior to intervention are associated with a worse functional outcome.

http://thejns.org/doi/abs/10.3171/2015.6.JNS15729

KEY WORDS decompressive hemicraniectomy; ischemic stroke; vascular disorders

$\mathrm{P}$ ATIENTS presenting with large ischemic strokes may develop uncontrollable, progressive brain edema that puts them at risk for compression of brain parenchyma and cerebral herniation. ${ }^{23}$ There are a limited number of therapeutic options, but research has shown that operative procedures, such as decompressive hemicraniectomy (DH), decrease patient mortality. ${ }^{32}$ Malignant in- farction treated only by conservative approaches results in a mortality rate of $80 \%$ within the 1 st week of the stroke. ${ }^{15}$ Edema that does not respond to medical treatment necessitates DH as a life-saving procedure. Studies have demonstrated that DH surgery can result in a reduction of mortality rate to $30 \%$ and, if decompression is performed within 24 hours of stroke onset, to $10 \%$. $^{7,12,18,24,32}$ While DH im-

ABBREVIATIONS BMI = body mass index; DH = decompressive hemicraniectomy; DVT = deep vein thrombosis; ICA = internal carotid artery; IVC = inferior vena cava; $\mathrm{MCA}=$ middle cerebral artery; $\mathrm{MI}=$ myocardial infarction; MLS = midline shift; $\mathrm{mRS}=$ modified Rankin Scale; NIHSS = National Institutes of Health Stroke Scale; tPA = tissue plasminogen activator.

SUBMITTED March 31, 2015. ACCEPTED June 17, 2015.

INCLUDE WHEN CITING Published online November 27, 2015; DOI: 10.3171/2015.6.JNS15729. 
proves patient survival, its effects on patients' functional outcome is still uncertain and the patient's family is presented with the difficult decision of choosing between intervention with DH and medical management. ${ }^{3}$ However, the long-term prognosis appears to be favorable if patients survive the acute phase of the stroke..$^{19}$ In addition, while the functional outcome of patients is not worsened by $\mathrm{DH}$, neurological deficit is likely as a result of initial large-territory ischemia.${ }^{15}$ The eligibility of patients with ischemic stroke to undergo DH might be further informed by functional outcome, mortality, and quality of life data. This information would be highly advantageous for patients and families to allow them to make informed decisions about patient care options. Patient selection for $\mathrm{DH}$ relies on neurological examination, baseline patient characteristics, stroke presentation, imaging evaluation, and time from onset of symptoms to surgery. ${ }^{22}$ The correlation of specific clinical variables preceding DH to patient outcome helps inform clinicians and families about the patient's potential prognosis. ${ }^{10}$ The current study inspects an array of clinical variables for potential predictors of functional outcome in patients who underwent $\mathrm{DH}$ for ischemic stroke.

\section{Methods}

\section{Patient Selection and Data Collection}

A total of 1624 patients who underwent any type of craniectomy from 2006 to 2014 were retrospectively screened via electronic medical record. The specific inclusion criterion was DH secondary to ischemic stroke involving the middle cerebral artery (MCA), internal carotid artery (ICA), or both. Individuals were excluded if they had undergone DH for any reason other than for ischemic stroke, or if the MCA or ICA was not implicated. Ninetyfive patients were identified. Demographic, radiographic, and treatment characteristics were recorded.

\section{Initial Treatment}

All patients with suspected acute ischemic stroke undergo immediate noncontrast CT scanning, CT angiography, and $\mathrm{CT}$ perfusion. Conservative treatment is administered in the ICU for blood pressure management, hyperthermia, and hyperglycemia control. Patients with malignant cerebral infractions are treated with osmotherapy with the use of intravenous mannitol or hypertonic saline, sedation, intubation with hyperventilation, diuretics, and steroids before DH. DH was performed either in response to deterioration in neurological status or as a preventive procedure in patients with space-occupying large hemispheric infarction with significant midline shift (MLS) documented on CT scans. Worsening clinical status was defined as pupillary dilation and signs of cerebral herniation or severe brain edema with mass effect despite medical treatment or hemorrhagic infarction. The timing of the DH procedure depended on the treating neurosurgeon and on other patient characteristics.

\section{Outcome}

The primary outcome was functional status assessed by modified Rankin Scale (mRS) score at 90 days and at the latest follow-up. The mRS ranges from 0 (no symptoms) to 6 (death), with intermediate values (1-5) representing increasing functional and cognitive disability. Poor functional outcome was defined as an mRS score of 4 (moderately severe disability), 5 (severe disability), or 6 (death). In comparison, scores of 0 (no symptoms), 1 (no substantial disability despite the presence of symptoms), 2 (slight disability, but not requiring assistance), and 3 (moderate disability necessitating some help) were considered as favorable outcomes. This categorization was based on physicians' attitudes regarding disability, with most physicians considering an mRS score of 3 as the cutoff between favorable and unfavorable outcome..$^{21}$

\section{Statistical Analysis}

Data are presented as mean \pm SD for continuous variables and as frequency for categorical variables. Analysis was carried out using unpaired t-test, chi-square test, and Fisher's exact tests. Univariate analysis was used to test covariates predictive of the following dependent variable: survival and poor functional outcome (mRS scores of 4-6). Interaction and confounding were assessed through stratification and relevant expansion covariates. Factors predictive in univariate analysis $(\mathrm{p}<0.20)$ were entered into a multivariate logistic regression analysis. A p value of $\leq 0.05$ was considered statistically significant. Statistical analysis was carried out with Stata 10.0.

\section{Results}

\section{Patient Characteristics and Outcomes}

The patient characteristics prior to DH are summarized in Table 1. There were 95 patients who presented with ischemic stroke involving the MCA (72\%), ICA (7\%), or both MCA and ICA (21\%) and underwent DH. Twenty-nine patients had infarction involving the dominant hemisphere (30.5\%) and 66 patients had a lesion in the nondominant hemisphere $(69.5 \%)$. The mean age was $57 \pm 12$ years, $60 \%$ were male, and the mean body mass index (BMI) was 28.3 $\pm 7.4 \mathrm{~kg} / \mathrm{m}^{2}$. Atrial fibrillation was diagnosed in $25 \%$ of patients, hypertension in $81 \%$, prior stroke in $20 \%$, diabetes in $33 \%$, and a previous myocardial infarction (MI) in 14\%. The mean National Institutes of Health Stroke Scale (NIHSS) score was $16 \pm 5$. Nineteen patients had signs of uncal herniation, with a unilaterally fixed and dilated pupil (20\%) prior to DH. Tissue plasminogen activator (tPA) was administered in $29 \%$ of subjects. In $19 \%$ of patients endovascular intervention was performed prior to $\mathrm{DH}$. The mean peak MLS was $9 \pm 5 \mathrm{~mm}$. Peak MLS measurements were based on radiological assessments of head CT scans by specialized neuroradiologists. The mean time from stroke onset to $\mathrm{DH}$ was $3 \pm 3$ days.

Outcomes are summarized in Table 2. Tracheostomy was performed in $36 \%$ and percutaneous endoscopic gastrostomy in $63 \%$ of subjects. Deep vein thrombosis (DVT) occurred in $36 \%$ of patients and an inferior vena cava (IVC) filter was placed in $25 \%$ of patients. Tracheostomy, percutaneous endoscopic gastrostomy, DVT, and IVC intervention occurred peri-DH. Subjects were hospitalized for a mean total of $22 \pm 17$ days, reflecting the severity of stroke, comorbidity, and requirement for prolonged intensive care. Most patients were discharged to a rehabilitation center $(58 \%)$. 
The mean mRS score at 90 days post-DH was $4 \pm 1$ characterized as moderately severe disability and functionally dependent. Seventy-three of 95 patients were further followed up for a mean period of 16.5 months; the remaining 22 patients did not have any available followup information after 90 days. At the last follow-up, the mean mRS was 4. Mortality (mRS score of 6) at 90 days post-DH was $18 \%$. There were 2 new deaths after the initial follow-up period (2\%). Four patients did not have any clinical follow-up at 90 days and mRS scores could not be obtained. At 90 days, mRS scores of 0 and 1 were not observed, and a score of 2 was observed in only 4 patients (4.4\%). An mRS score of 3 (35.2\%) represented outcome in the majority of patients in the less severe functional outcome category. Poor functional outcome was observed in $58 \%$ of patients, with scores of $4(31 \%), 5(9 \%)$, and $6(18 \%)$. At the latest follow-up, poor functional outcome was observed in $52 \%$ of patients (Table 2).

\section{Predictors of Poor Functional Outcome}

Patient demographics and clinical characteristics were investigated in relationship to $\mathrm{mRS}$ scores to identify potential predictors of poor functional outcome (Table 3). In univariate analysis, patients with a history of stroke, history of MI, MLS > $10 \mathrm{~mm}$, or increasing MLS were significantly more likely to have a poor functional outcome (mRS Scores 4-6) at 90 days post-DH. Patients with a history of stroke were predicted to be 6.54 times more likely to develop a poor functional outcome than those without a history of stroke (95\% CI 1.39-30.66; $\mathrm{p}=0.017$ ). History of MI predicted a nearly 9 times greater likelihood of poor functional outcome than no such history $(95 \%$ CI $1.10-72.76 ; \mathrm{p}=0.040)$. Patients with an increasing peak MLS (OR 1.1 [95\% CI 1.01-1.22]; $\mathrm{p}=0.039$ ) or peak MLS $>10 \mathrm{~mm}$ (OR 3.35 [95\% CI 1.33-8.47]; p = 0.011) had a greater likelihood of poor functional outcome. Other parameters of note correlated with elevated odds of mRS Scores 4-6 but did not reach statistical significance: age $>65$ years (OR 1.41), BMI > $30 \mathrm{~kg} / \mathrm{m}^{2}$ (OR 1.14), NIHSS score $>17$ (OR 1.88), intravenous tPA (OR 1.17), diabetes mellitus (OR 2.23), seizures (OR 1.6), IVC filter (OR 1.21), atrial fibrillation (OR 1.86), and smoking (OR 1.24).

In the multivariate analysis (Table 4), patients with an MLS > $10 \mathrm{~mm}$, adjusting for age, history of stroke, diabetes, pupillary dilation, and hemisphere involved, were 5.15 times more likely to have a poor functional outcome after DH than those with less MLS (95\% CI 1.58-16.79; $\mathrm{p}=0.007$ ). Thus, MLS $>10 \mathrm{~mm}$ is a strong predictor of poor functional outcome, irrespective of age, prior stroke, diabetes, pupillary response, or hemisphere involved. Similarly, patients with a history of stroke, adjusting for age, MLS > $10 \mathrm{~mm}$, diabetes, pupillary response, and hemisphere involved, were 9.14 times more likely to have poor outcome than those without a history of stroke $(95 \%$ CI 1.78-47.05; $\mathrm{p}=0.008$ ). Patients with diabetes were likely to develop poor outcome when adjusting for age, MLS $>10 \mathrm{~mm}$, history of stroke, pupillary dilation, and hemisphere than patients without diabetes (OR 5.63; 95\% CI 1.52-20.88; $\mathrm{p}=0.01)$. Increasing days from onset of stroke symptoms to $\mathrm{DH}$ was a significant predictor of poor outcome when adjusting for MLS $>10 \mathrm{~mm}$, NIHSS
TABLE 1. Baseline characteristics

\begin{tabular}{|c|c|}
\hline Characteristic & Value (\%) \\
\hline No. of patients & 95 \\
\hline \multicolumn{2}{|l|}{ Age, yrs } \\
\hline Mean* & $57 \pm 12$ \\
\hline Range & $22-82$ \\
\hline \multicolumn{2}{|l|}{ Sex, no. } \\
\hline Male & $57(60)$ \\
\hline Female & $38(40)$ \\
\hline \multicolumn{2}{|l|}{ BMI, $\mathrm{kg} / \mathrm{m}^{2}$} \\
\hline Mean* & $28.3 \pm 7.4$ \\
\hline Range & $14.5-66.9$ \\
\hline \multicolumn{2}{|l|}{ Comorbidities, no. } \\
\hline Hypertension & $77(81)$ \\
\hline Hyperlipidemia & $39(41)$ \\
\hline Smoking & $37(39)$ \\
\hline Diabetes & $31(33)$ \\
\hline Atrial fibrillation & $24(25)$ \\
\hline Prior stroke(s) & $19(20)$ \\
\hline $\mathrm{Ml}$ & $13(14)$ \\
\hline Seizures & $12(13)$ \\
\hline \multicolumn{2}{|l|}{ Infarct site, no. } \\
\hline \multicolumn{2}{|l|}{ MCA } \\
\hline Right & $43(46)$ \\
\hline Left & $21(22)$ \\
\hline Bilateral & $4(4)$ \\
\hline \multicolumn{2}{|l|}{ ICA } \\
\hline Right & $2(2)$ \\
\hline Left & $3(3)$ \\
\hline Bilateral & $2(2)$ \\
\hline MCA \& ICA & $20(21)$ \\
\hline \multicolumn{2}{|l|}{ NIHSS total score } \\
\hline Mean* & $16 \pm 5$ \\
\hline Range & $1-32$ \\
\hline \multicolumn{2}{|l|}{ Acute intervention, no. } \\
\hline Intravenous tPA & $28(29)$ \\
\hline Endovascular & $18(19)$ \\
\hline \multicolumn{2}{|l|}{ Peak MLS, mm } \\
\hline Mean* & $9 \pm 5$ \\
\hline Range & $0-19$ \\
\hline Mean days from symptom onset to $\mathrm{DH}$ & $3 \pm 3$ \\
\hline Dom hemisphere/nondom hemisphere & $29(30.5) / 66(69.5)$ \\
\hline Pupillary dilation preop & $19(20)$ \\
\hline
\end{tabular}

Dom = dominant; nondom = nondominant.

* Mean values are presented \pm SD.

score $>17$, history of stroke, and MI (OR 1.32; 95\% CI $1.02-1.72 ; \mathrm{p}=0.037)$. Furthermore, pupillary dilation was significantly associated with higher odds of poor outcome when controlling for age, MLS, history of stroke, diabetes, and cerebral hemisphere (OR 4.19; 95\% CI 1.06-16.51; $\mathrm{p}=0.04)$. Patients with cerebral infarction involving the dominant hemisphere had higher odds of unfavorable 
TABLE 2. Outcomes of ischemic stroke patients after decompressive hemicraniectomy*

\begin{tabular}{|c|c|}
\hline Outcome & Value (\%) \\
\hline \multicolumn{2}{|l|}{ Hospital duration, days } \\
\hline Mean & $22 \pm 17$ \\
\hline Range & $3-101$ \\
\hline Tracheostomy, no. & $35(36)$ \\
\hline Gastrostomy, no. & $60(63)$ \\
\hline DVT, no. & $34(36)$ \\
\hline IVC filter, no. & $24(25)$ \\
\hline \multicolumn{2}{|l|}{ Discharge location, no. } \\
\hline Rehabilitation center & $55(58)$ \\
\hline Nursing home & $11(12)$ \\
\hline Rehabilitation/nursing & $4(4)$ \\
\hline Long-term acute care & $8(8)$ \\
\hline Hospice & $2(2)$ \\
\hline Not known & $15(16)$ \\
\hline \multicolumn{2}{|c|}{$\begin{array}{l}\text { mRS score at } 90 \text { days post-DH/mRS score at } \\
\text { last FU† }\end{array}$} \\
\hline 0 & $0(0) / 0(0)$ \\
\hline 1 & $0(0) / 0(0)$ \\
\hline 2 & $4(4.4) / 18(24.7)$ \\
\hline 3 & $32(35.2) / 17$ (23.3) \\
\hline 4 & $29(31) / 17(23.3)$ \\
\hline 5 & $9(9) / 2(2.7)$ \\
\hline 6 (death) & $17(18) / 19(26)$ \\
\hline Mean & $4 \pm 1$ \\
\hline Median & 4 \\
\hline \multicolumn{2}{|c|}{$\begin{array}{l}\text { FU }=\text { follow-up. } \\
{ }^{*} \text { Values are presented as the number }(\%) \text { of patients unless otherwise speci- } \\
\text { fied. } \\
\dagger \text { mRS scores unknown at } 90 \text { days }(n=4) / m R S \text { scores unknown at later } \\
\text { follow-up }(n=22) \text {. }\end{array}$} \\
\hline
\end{tabular}

functional outcome at 90 days than their counterparts (OR 4.73 ; 95\% CI 1.36-16.44; $\mathrm{p}=0.014$ ), but when this association was tested at the latest follow-up period (mean 16.5 months), cerebral dominance was not significantly related to outcome (OR 1.63, 95\% CI 0.61-4.34; $\mathrm{p}=0.328$ ).

\section{Discussion}

The present analysis describes the clinical variables and functional outcomes in patients who underwent DH subsequent to severe cerebral edema that resulted from ischemic stroke.

Decompressive hemicraniectomy can be a life-saving procedure. $8,11,14,30,31$ Its beneficial effects may vary among patients. In this study, we set out to identify risk factors that can be associated with increased mortality rate and poor outcome after surgery and aid the patient selection for $\mathrm{DH}$. The main factors that were significant predictors of poor outcome were a history of stroke, a history of diabetes, a prior history of MLS, a peak MLS > $10 \mathrm{~mm}$, and increasing duration from onset of stroke to $\mathrm{DH}$.

The mortality rates were $18 \%$ and $20 \%$ at 90 days and at
TABLE 3. Univariate analysis of predictors of poor functional outcome (i.e., mRS Scores 4-6)

\begin{tabular}{lccc}
\hline \multicolumn{1}{c}{ Clinical Variable } & OR & p Value & $95 \% \mathrm{Cl}$ \\
\hline Increasing age & 1.03 & 0.106 & $0.99-1.07$ \\
\hline Age $>65$ yrs & 1.41 & 0.507 & $0.51-3.94$ \\
\hline Sex & 0.59 & 0.228 & $0.25-1.39$ \\
\hline BMI & 1.01 & 0.802 & $0.95-1.07$ \\
\hline BMI $>30 \mathrm{~kg} / \mathrm{m}^{2}$ & 1.14 & 0.800 & $0.42-3.09$ \\
\hline Increasing MLS & 1.11 & 0.039 & $1.01-1.22$ \\
\hline MLS $>10$ mm & 3.35 & 0.011 & $1.33-8.47$ \\
\hline NIHSS score & 1.06 & 0.216 & $0.97-1.15$ \\
\hline NIHSS score $>17$ & 1.88 & 0.165 & $0.77-4.59$ \\
\hline Increasing days from onset to DH & 1.20 & 0.073 & $0.98-1.46$ \\
\hline tPA intervention & 1.17 & 0.735 & $0.47-2.96$ \\
\hline Endovascular intervention & 0.9 & 0.853 & $0.30-2.74$ \\
\hline Hyperlipidemia & 0.99 & 0.989 & $0.44-2.25$ \\
\hline History of & & & \\
\hline \multicolumn{1}{c}{ Stroke } & 6.54 & 0.017 & $1.39-30.66$ \\
\hline Diabetes & 2.23 & 0.101 & $0.85-5.80$ \\
\hline MI & 8.95 & 0.040 & $1.10-72.76$ \\
\hline Seizures & 1.6 & 0.450 & $0.47-5.42$ \\
\hline IVC filter & 1.21 & 0.693 & $0.46-3.17$ \\
\hline Atrial fibrillation & 1.86 & 0.204 & $0.71-4.87$ \\
\hline Tobacco & 1.24 & 0.628 & $0.51-3.01$ \\
\hline Dom hemisphere & 2.76 & 0.043 & $1.03-7.40$ \\
\hline Evidence of pupillary dilation & 1.54 & 0.426 & $0.52-4.53$ \\
\hline
\end{tabular}

the latest follow-up, respectively. A good clinical outcome (mRS score of $\leq 3$ ) was observed in about $40 \%$ of patients at 90 days and $48 \%$ after more than a year of follow-up. These results are comparable to the results reported by the major clinical trials. The DECIMAL trial reported mRS scores of $\leq 3$ at 6-month and 1-year follow-up of $25 \%$ and $50 \%$, respectively, after DH (compared with $5.6 \%$ and $22.2 \%$ in the medical treatment group). ${ }^{31}$ The DESTINY trial reported that $88 \%$ of patients who underwent hemicraniectomy survived after 30 days (compared with $47 \%$ of patients randomized to conservative therapy), and $47 \%$ of patients in the surgical arm had an mRS score of 0-3 at 12 months (compared with $27 \%$ of patients in the conservative treatment arm). ${ }^{14}$ The HeADDFIRST trial reported that the mortality rates at 21 and 180 days were $21 \%$ and $36 \%$ in patients who received surgical treatment. ${ }^{8}$ Vahedi et al. conducted a pooled analysis of the major trials and reported that $43 \%$ of patients in the decompressive surgery group had an mRS score of $\leq 3$ (compared with $21 \%$ who received medical management), and the mortality rate was $22 \%$ (compared with $71 \%$ ). ${ }^{30}$

The ages of patients who underwent $\mathrm{DH}$ ranged from 22 to 82 in the present study. The main studies that have evaluated the role of $\mathrm{DH}$ excluded patients older than 60 years, and early reports concluded that people older than 60 years do not benefit from DH. $\cdot^{3,11,14,31}$ However, since the time those studies were published, there has been an increasing amount of evidence that this procedure is ben- 
TABLE 4. Multivariate analysis of poor functional outcome (i.e., mRS Scores 4-6)

\begin{tabular}{|c|c|c|c|c|c|}
\hline \multirow[b]{2}{*}{ Clinical Variable } & \multicolumn{2}{|c|}{ Univariate Analysis } & \multicolumn{3}{|l|}{ Multivariate Analysis } \\
\hline & OR $(95 \% \mathrm{Cl})$ & $\mathrm{p}$ Value & Adjusted for & OR $(95 \% \mathrm{Cl})$ & $\mathrm{p}$ Value \\
\hline MLS >10 mm & $3.35(1.33-8.47)$ & 0.011 & Hx of stroke, DM, age, pupillary dilation, hemisphere involved & $5.15(1.58-16.79)$ & 0.007 \\
\hline Hx of stroke & $6.54(1.39-30.66)$ & 0.017 & MLS >10 mm, DM, age, pupillary dilation, hemisphere involved & $9.14(1.78-47.05)$ & 0.008 \\
\hline $\mathrm{Hx}$ of $\mathrm{DM}$ & $2.23(0.85-5.80)$ & 0.101 & $\begin{array}{l}\text { MLS >10 mm, } \mathrm{Hx} \text { of stroke, age, pupillary dilation, hemisphere } \\
\text { involved }\end{array}$ & $5.63(1.52-20.88)$ & 0.01 \\
\hline $\mathrm{Hx}$ of $\mathrm{Ml}$ & $8.95(1.10-72.76)$ & 0.040 & MLS $>10 \mathrm{~mm}, \mathrm{Hx}$ of stroke, DM & $4.70(0.54-40.83)$ & 0.160 \\
\hline $\begin{array}{l}\text { Increasing days btwn } \\
\text { stroke \& DH }\end{array}$ & $1.20(0.98-1.46)$ & 0.073 & MLS $>10 \mathrm{~mm}$, NIHSS $>17$, Hx of stroke, MI & $1.32(1.02-1.72)$ & 0.037 \\
\hline Pupillary dilation & $1.54(90.52-4.53)$ & 0.426 & MLS >10 mm, Hx of stroke, DM, hemisphere involved & $4.19(1.06-16.51)$ & 0.04 \\
\hline Dom hemisphere & $2.76(1.03-7.40)$ & 0.043 & MLS >10 mm, Hx of stroke, pupillary dilation, DM & $4.73(1.36-16.44)$ & 0.014 \\
\hline
\end{tabular}

$\mathrm{DM}=$ diabetes mellitus; $\mathrm{Hx}=$ history.

eficial in patients older than 60 years of age and that in fact it can be a life-saving procedure in these patients. ${ }^{15,35,36}$ Some studies have suggested that $\mathrm{DH}$ improves survival but results in poor clinical outcome. In our study, in both univariate and multivariate analyses, age was not a significant predictor of clinical outcome and patients older than 65 years did not have higher odds of experiencing a poor outcome. Age may not have been predictive due to selection bias. Most of the surgically treated patients were younger than 65 years (mean 56.6 years, but $75 \%$ were younger than 65 years and $90 \%$ were younger than 73). However, recently the DESTINY II trial reported that hemicraniectomy significantly improves survival without being associated with severe disability in patients 61 years of age and older (38\%) compared with $18 \%$ in the control group with a lower mortality rate in the surgery group (33\% vs 70\%). ${ }^{15}$ Furthermore, Zhao et al. have reported that the benefit of the procedure can be extended to patients 80 years of age. ${ }^{36}$ Therefore, DH should be considered in older patients and patient selection should not be limited to age.

Other important individual characteristics to consider in the selection for DH procedure include patient comorbidities. Not many studies looked at specific comorbidities and evaluated their effect on outcome after surgery. History of diabetes, a previous stroke, and history of MLS were significant predictors of poor functional outcome. Patients with these comorbidities may have some level of functional decline prior to stroke and are more likely to have postoperative complications; therefore, functional outcomes will be worsened after DH. It is important to note that since the incidence of these comorbidities increases with age, older patients may seem to be at a higher risk of poor functional outcome and age may seem to be a stronger predictor of poor clinical outcome. However, that association may be partly due to the accompanying medical problems that are more likely to be present in older patients. ${ }^{26}$ Therefore, it is important to assess each case separately and make individualized decisions for each patient and take into account not only age, but other comorbidities that significantly affect outcome.

Time from onset of stroke to decompression is a crucial factor in the management of malignant cerebral infarction. Decompressive hemicraniectomy has been shown to be most effective when performed early, within 48 hours. ${ }^{4,13,20,24,25}$ In the current study, there was a wide variation in the time to $\mathrm{DH}$ with a mean of 3 days after symptom onset. Surgery was done in $60 \%$ of patients within the first 48 hours and $73 \%$ of patients within the first 72 hours. Patients who had more prolonged interventions had significantly higher odds of poor outcome at 90 days. The HAMLET trial reported that surgical decompression reduced case fatality and poor outcome in patients with space-occupying infarctions who were treated within 48 hours of stroke onset, but found no significant benefit after 96 hours. ${ }^{11}$ Early surgical decompression is most effective in lowering elevated intracranial pressure and preventing transtentorial herniation. Furthermore, pupillary dilation can develop within the first 3 to 5 days and may indicate the presence of significant brainstem shift and clinical deterioration. ${ }^{33}$ Patients with pupillary abnormalities were significantly more likely to have poor outcomes. Waiting for evidence of pupillary dilation can impede early intervention and worsens prognosis. Early intervention should be performed prior to the occurrence of this clinical sign when possible.

The MLS was serially monitored by neuroradiology for patients with cerebral edema. The peak value was collected, with a mean shift of $9 \mathrm{~mm}$ prior to intervention with DH. The mean MLS for patients who had a favorable outcome was $7.4 \mathrm{~mm}$, whereas the mean MLS for patients with poor outcome was $10 \mathrm{~mm}$. A higher peak MLS prior to surgery and MLS $\geq 10 \mathrm{~mm}$ significantly worsened outcome after DH. This is related to an increased mass effect and risk of brain herniation with compression of vital structures and hemodynamically, higher impairment of autoregulation. ${ }^{1,17}$

Decompressive hemicraniectomies for MCA- and ICA-territory infarcts were included in this study. Acute ICA-territory infarctions usually have a poorer prognosis than MCA-territory infarction, and cerebral edema is more severe. ${ }^{34}$ All patients with ICA infarctions had a poor outcome at 90 days, but none died. The role of $\mathrm{DH}$ in the management of ICA infarcts is less well established. Several studies failed to find a significant improvement in outcome after DH in patients with such infarctions. ${ }^{17,32,34}$ Our results show that functional outcome is unlikely to improve in these patients even after $\mathrm{DH}$, but the survival 
of these patients should be highlighted, suggesting decompression's positive effect on mortality in patients with malignant ICA infarction.

At 90 days following presentation, $75.9 \%$ of patients with a dominant-hemisphere infarction had poor outcome compared to $53.2 \%$ of patients with nondominanthemisphere involvement. This difference was significant. However, further along in the follow-up period (mean 16.5 months), $60 \%$ of patients with a dominant-hemisphere infarction had an unfavorable outcome compared to $48 \%$ of patients with nondominant-hemisphere involvement, a nonsignificant difference. The debate regarding $\mathrm{DH}$ in patients with involvement of the dominant hemisphere stems from the hypothesis that aphasia with loss of communication leads to poor outcome. ${ }^{24,27}$ A significant improvement in aphasia and a better overall outcome, however, have been observed with longer follow-ups. ${ }^{5,16}$ Involvement of the dominant cerebral hemisphere should not preclude surgical decompression because long-term differences in clinical outcome after DH are not significantly different from those seen in patients with nondominant-hemisphere infarctions. $9,27,29$

Intravenous tPA administration was not a significant predictor of poor outcome after DH. Several other studies have failed to find a significant effect of tPA administration on poor outcome and mortality after surgery as well. ${ }^{2,6,28}$ In the present study $29 \%$ of patients received intravenous tPA prior to $\mathrm{DH}$. Although the theoretical risk of increased bleeding during and after the procedure exists, cases involving tPA intervention or endovascular therapy should not exclude the need for DH.

Depending on the severity of the stroke, patients required tracheostomy for ventilatory assistance and percutaneous endoscopic gastrostomy tube placement to provide a route for adequate nutrition. The incidence of DVT (36\%) and the need for placement of an IVC filter (25\%) were not uncommon during the inpatient recovery period. After total hospitalization for nearly a month, patients were typically discharged to a rehabilitation center. At 90 days post-DH, most patients had disability requiring assistance (mRS scores of 3-5), a minority of patients (4\%) were considered functionally independent (mRS score of 2 ), and $18 \%$ of patients were dead (mRS score of 6). An mRS score of 0 (no symptoms) or 1 (no disability despite symptoms) was not observed.

The main limitations of this study include its retrospective single-center nature, which may limit the generalizability of the study, the fact that it did not control for patients without $\mathrm{DH}$ receiving intensive medical care, and the subjective nature of the mRS scoring system that was used as a measure of outcome.

\section{Conclusions}

Clinical markers such as history of stroke, diabetes, and MI; peak MLS (> $10 \mathrm{~mm}$ ); time from onset of symptoms to surgery; and evidence of pupillary dilation may provide important prognostic information for predicting poor functional outcome (mRS score of 4-6) in candidates for $\mathrm{DH}$ as a result of large ischemic stroke. Based on the description of baseline patient characteristics, individual patients are likely to present with multiple factors that make it difficult to accurately estimate functional outcome. This stratified array of clinical information is intended to help guide clinicians in estimating functional outcome. Clinical decision making of whether to perform $\mathrm{DH}$ takes into account a variety of factors that cannot always be rigidly defined and are not always abundantly clear. As such, additional considerations must be weighed and are combined with objective clinical predictive information to guide decision making.

\section{References}

1. Amorim RL, de Andrade AF, Gattás GS, Paiva WS, Menezes M, Teixeira MJ, et al: Improved hemodynamic parameters in middle cerebral artery infarction after decompressive craniectomy. Stroke 45:1375-1380, 2014

2. Baharvahdat H, Etemadrezaie H, Zabyhian S, Valipour Z, Ganjeifar B, Mousavi Mirzaye SM, et al: Decompressive craniectomy after unsuccessful intravenous thrombolysis of malignant cerebral infarction. Iran J Neurol 13:101-104, 2014

3. Chen CC, Cho DY, Tsai SC: Outcome of and prognostic factors for decompressive hemicraniectomy in malignant middle cerebral artery infarction. J Clin Neurosci 14:317-321, 2007

4. Cho DY, Chen TC, Lee HC: Ultra-early decompressive craniectomy for malignant middle cerebral artery infarction. Surg Neurol 60:227-233, 2003

5. Delashaw JB, Broaddus WC, Kassell NF, Haley EC, Pendleton GA, Vollmer DG, et al: Treatment of right hemispheric cerebral infarction by hemicraniectomy. Stroke 21:874-881, 1990

6. Fischer U, Taussky P, Gralla J, Arnold M, Brekenfeld C, Reinert M, et al: Decompressive craniectomy after intra-arterial thrombolysis: safety and outcome. J Neurol Neurosurg Psychiatry 82:885-887, 2011

7. Foerch C, Lang JM, Krause J, Raabe A, Sitzer M, Seifert V, et al: Functional impairment, disability, and quality of life outcome after decompressive hemicraniectomy in malignant middle cerebral artery infarction. J Neurosurg 101:248-254, 2004

8. Frank JI, Schumm LP, Wroblewski K, Chyatte D, Rosengart AJ, Kordeck C, et al: Hemicraniectomy and durotomy upon deterioration from infarction-related swelling trial: randomized pilot clinical trial. Stroke 45:781-787, 2014

9. Gupta R, Connolly ES, Mayer S, Elkind MS: Hemicraniectomy for massive middle cerebral artery territory infarction: a systematic review. Stroke 35:539-543, 2004

10. Hacke W, Schwab S, Horn M, Spranger M, De Georgia M, von Kummer R: 'Malignant' middle cerebral artery territory infarction: clinical course and prognostic signs. Arch Neurol 53:309-315, 1996

11. Hofmeijer J, Kappelle LJ, Algra A, Amelink GJ, van Gijn J, van der Worp HB: Surgical decompression for space-occupying cerebral infarction (the Hemicraniectomy After Middle Cerebral Artery infarction with Life-threatening Edema Trial [HAMLET]): a multicentre, open, randomised trial. Lancet Neurol 8:326-333, 2009

12. Holtkamp M, Buchheim K, Unterberg A, Hoffmann O, Schielke E, Weber JR, et al: Hemicraniectomy in elderly patients with space occupying media infarction: improved survival but poor functional outcome. J Neurol Neurosurg Psychiatry 70:226-228, 2001

13. Jüttler E, Hacke W: Early decompressive hemicraniectomy in older patients with nondominant hemispheric infarction improves outcome. Stroke 42:843-844, 2011

14. Jüttler E, Schwab S, Schmiedek P, Unterberg A, Hennerici M, Woitzik J, et al: Decompressive Surgery for the Treatment of Malignant Infarction of the Middle Cerebral Artery (DESTINY): a randomized, controlled trial. Stroke 38:2518-2525, 2007 
15. Jüttler E, Unterberg A, Woitzik J, Bösel J, Amiri H, Sakowitz OW, et al: Hemicraniectomy in older patients with extensive middle-cerebral-artery stroke. N Engl J Med 370:1091-1100, 2014

16. Kastrau F, Wolter M, Huber W, Block F: Recovery from aphasia after hemicraniectomy for infarction of the speechdominant hemisphere. Stroke 36:825-829, 2005

17. Kilincer C, Asil T, Utku U, Hamamcioglu MK, Turgut N, Hicdonmez T, et al: Factors affecting the outcome of decompressive craniectomy for large hemispheric infarctions: a prospective cohort study. Acta Neurochir (Wien) 147:587-594, 2005

18. Leonhardt G, Wilhelm H, Doerfler A, Ehrenfeld CE, Schoch B, Rauhut F, et al: Clinical outcome and neuropsychological deficits after right decompressive hemicraniectomy in MCA infarction. J Neurol 249:1433-1440, 2002

19. Malm J, Bergenheim AT, Enblad P, Hårdemark HG, Koskinen LO, Naredi S, et al: The Swedish Malignant Middle cerebral artery Infarction Study: long-term results from a prospective study of hemicraniectomy combined with standardized neurointensive care. Acta Neurol Scand 113:25-30, 2006

20. Merenda A, DeGeorgia M: Craniectomy for acute ischemic stroke: how to apply the data to the bedside. Curr Opin Neurol 23:53-58, 2010

21. Neugebauer H, Creutzfeldt CJ, Hemphill JC III, Heuschmann PU, Jüttler E: DESTINY-S: attitudes of physicians toward disability and treatment in malignant MCA infarction. Neurocrit Care 21:27-34, 2014

22. Rahme R, Curry R, Kleindorfer D, Khoury JC, Ringer AJ, Kissela BM, et al: How often are patients with ischemic stroke eligible for decompressive hemicraniectomy? Stroke 43:550-552, 2012

23. Ropper AH, Shafran B: Brain edema after stroke. Clinical syndrome and intracranial pressure. Arch Neurol 41:26-29, 1984

24. Schwab S, Steiner T, Aschoff A, Schwarz S, Steiner HH, Jansen O, et al: Early hemicraniectomy in patients with complete middle cerebral artery infarction. Stroke 29:1888-1893, 1998

25. Staykov D, Gupta R: Hemicraniectomy in malignant middle cerebral artery infarction. Stroke 42:513-516, 2011

26. Subramaniam S, Hill MD: Decompressive hemicraniectomy for malignant middle cerebral artery infarction: an update. Neurologist 15:178-184, 2009

27. Sundseth J, Sundseth A, Thommessen B, Johnsen LG, Altmann M, Sorteberg W, et al: Long-term outcome and quality of life after craniectomy in speech-dominant swollen middle cerebral artery infarction. Neurocrit Care 22:6-14, 2015

28. Takeuchi S, Wada K, Nawashiro H, Arimoto H, Ohkawa H, Masaoka H, et al: Decompressive craniectomy after intravenous tissue plasminogen activator administration for stroke. Clin Neurol Neurosurg 114:1312-1315, 2012

29. Uhl E, Kreth FW, Elias B, Goldammer A, Hempelmann RG, Liefner M, et al: Outcome and prognostic factors of hemicra- niectomy for space occupying cerebral infarction. J Neurol Neurosurg Psychiatry 75:270-274, 2004

30. Vahedi K, Hofmeijer J, Juettler E, Vicaut E, George B, Algra $A$, et al: Early decompressive surgery in malignant infarction of the middle cerebral artery: a pooled analysis of three randomised controlled trials. Lancet Neurol 6:215-222, 2007

31. Vahedi K, Vicaut E, Mateo J, Kurtz A, Orabi M, Guichard JP, et al: Sequential-design, multicenter, randomized, controlled trial of early decompressive craniectomy in malignant middle cerebral artery infarction (DECIMAL Trial). Stroke 38:2506-2517, 2007

32. Walz B, Zimmermann C, Böttger S, Haberl RL: Prognosis of patients after hemicraniectomy in malignant middle cerebral artery infarction. J Neurol 249:1183-1190, 2002

33. Wijdicks EF, Sheth KN, Carter BS, Greer DM, Kasner SE, Kimberly WT, et al: Recommendations for the management of cerebral and cerebellar infarction with swelling: a statement for healthcare professionals from the American Heart Association/American Stroke Association. Stroke 45:12221238,2014

34. Yoo SH, Kim TH, Shin JJ, Shin HS, Hwang YS, Park SK: The clinical efficacy of decompressive craniectomy in patients with an internal carotid artery territory infarction. $\mathbf{J}$ Korean Neurosurg Soc 52:293-299, 2012

35. Yu JW, Choi JH, Kim DH, Cha JK, Huh JT: Outcome following decompressive craniectomy for malignant middle cerebral artery infarction in patients older than 70 years old. J Cerebrovasc Endovasc Neurosurg 14:65-74, 2012

36. Zhao J, Su YY, Zhang Y, Zhang YZ, Zhao R, Wang L, et al: Decompressive hemicraniectomy in malignant middle cerebral artery infarct: a randomized controlled trial enrolling patients up to 80 years old. Neurocrit Care 17:161-171, 2012

\section{Disclosures}

Dr. Jabbour reports being a consultant for Covidien.

\section{Author Contributions}

Conception and design: Jabbour. Acquisition of data: Daou, Kent, Montano. Analysis and interpretation of data: Daou, Kent, Montano, Chalouhi, Starke. Drafting the article: Jabbour, Daou, Kent, Montano. Critically revising the article: Jabbour, Chalouhi, Tjoumakaris, Rosenwasser. Reviewed submitted version of manuscript: Jabbour, Tjoumakaris. Statistical analysis: Starke. Study supervision: Jabbour, Tjoumakaris, Rosenwasser.

\section{Correspondence}

Pascal M. Jabbour, Division of Neurovascular Surgery and Endovascular Neurosurgery, Department of Neurological Surgery, Thomas Jefferson University Hospital, 901 Walnut St., 3rd Fl., Philadelphia, PA 19107. email: pascal.jabbour@jefferson. edu. 